\title{
Typhoidal Salmonella and Emerging Resistance in Outbreak Proportions
}

\author{
Bindu Poonia' ${ }^{1}$ Inam Danish Khan ${ }^{1 *}$, Anuradha Makkar', KS Rajmohan', Deepak Kumar ${ }^{1}$, Amandeep Malik ${ }^{1}$, \\ Shilpi Gupta ${ }^{2}$, Priyanka Banerjee', Pragyan Swagatika Panda' ${ }^{1}$, Rajiv Mohan Gupta ${ }^{3}$
}

${ }^{1}$ Army College of Medical Sciences and Base Hospital, New Delhi, India

${ }^{2}$ Graded Specialist Microbiology, Military Hospital Bhopal, New Delhi, India

${ }^{3}$ Army Hospital Research and Referral, New Delhi, India

Corresponding Author: Inam Danish Khan, MD, Assistant Professor of Microbiology, Army College of Medical Sciences and Base Hospital, New Delhi 110010, India. Tel: +91-8076324060, Fax: +91-1125693490, Email: titan_afmc@yahoo.com,

Received December 10, 2017; Accepted February 4, 2018; Online Published April 9, 2018

\begin{abstract}
Introduction: Typhoidal Salmonella causes an invasive infection resulting in 200000 deaths among 20 million patients annually. Typhoid remains a public health problem in Southeast Asia, the Indian subcontinent, Africa, and South America. Traveler's diarrhea caused by Salmonella is common in Asia. Outbreaks of typhoidal Salmonella resistant to ampicillin, chloramphenicol, and trimethoprimsulfamethoxazole in the 1990s pushed therapy to ciprofloxacin which was replaced by ceftriaxone due to fluoroquinolone resistance. Methods: This prospective study characterizes demographical, etiological, and resistance patterns in typhoidal Salmonella at a 1000-bed teaching hospital in New Delhi, India. Two hundred inpatients in pediatrics, obstetrics-gynecology, medicine, intensive care, and OPD in whom Salmonella bacteremia was detected were characterized by routine and automated microbiology techniques.

Results: The mean age of patients in this study was 21.4 years. Overall, $71 \%$ of patients suffered from Salmonella Typhi followed by $26 \%$ from Salmonella Paratyphi A. Four cases of Salmonella resistance to ampicillin, trimethoprim-sulfamethoxazole, and chloramphenicol were encountered. A high degree of partial and complete resistance to fluoroquinolones was seen among Salmonella Typhi, Salmonella Paratyphi A, and Salmonella Paratyphi B cases. Resistance to ciprofloxacin was 48\% among Salmonella Typhi and 100\% among Salmonella Paratyphi A cases. Only $18 \%$ of Salmonella Typhi cases were completely resistant to quinolones, while $79 \%$ were partially resistant. A total of $92 \%$ of Salmonella Paratyphi A cases were partially resistant to quinolones. Four Salmonella cases were resistant to ceftriaxone. Conclusion: Salmonella Typhi remains the predominant serotype, followed by Salmonella Paratyphi A. The high prevalence of quinolone resistance in Salmonella Typhi and Salmonella Paratyphi A is a serious problem limiting empirical therapy to non-quinolone-based therapy such as ceftriaxone. Multidrug-resistant Salmonella is an emerging problem requiring active surveillance among residents and travelers presenting with tropical fever.
\end{abstract}

Keywords: Salmonella, Typhoid, Multidrug Resistance, Fluoroquinolone Resistance, Traveler's Diarrhea

Citation: Poonia B, Khan ID, Makkar A, et al. Typhoidal Salmonella and emerging resistance in outbreak proportions. Int J Travel Med Glob Health 2018;6(2):64-68. doi:10.15171/ijtmgh.2018.12.

\section{Introduction}

Salmonella enterica subspecies enterica serotypes Typhi, Paratyphi A, Paratyphi B and Paratyphi C cause an acute, invasive and potentially fatal systemic infection known as typhoid fever or enteric fever. Among the 12 to 22 million patients of typhoid fever per annum, the estimated death rate is between 129000 and 217000 , and $80 \%$ of these cases and deaths occur in Asia alone. Due to improved sanitation, most developed countries in Europe and North America are free from enteric fever, but enteric fever is still a disease of concern in Southeast Asia, the Indian subcontinent, Africa, and, to a lesser extent, in South America. ${ }^{1-3}$ Regions with the highest incidence of enteric fever are South-Central Asia and
Southeast Asia. Salmonella has been responsible for numerous outbreaks in the Indian subcontinent, Southeast Asia, and Africa. In Delhi, India, the incidence rate is 9.8 cases/1000 person per year. ${ }^{4-6}$

Salmonella is a common cause of traveler's diarrhea presenting with fever, nausea, vomiting, and abdominal cramps. Up to $70 \%$ of travelers from Western countries develop traveler's diarrhea in the first week of travel to tropical destinations in South Asia and Southeast Asia. Highrisk regions for traveler's diarrhea are Asia, the Middle East, Africa, Mexico, Central and South America. Intermediate-risk regions are Eastern Europe, South Africa, and some Caribbean islands. Low-risk regions are Northern and Western Europe,

Copyright $(\subset 2018$ The Author(s). This is an open-access article distributed under the terms of the Creative Commons Attribution License (http:// creativecommons.org/licenses/by/4.0), which permits unrestricted use, distribution, and reproduction in any medium, provided the original work is properly cited. 
the United States, Canada, Australia, New Zealand, and Japan. A large number of traveler's take empirical ciprofloxacin or azithromycin to reduce the severity and duration of traveler's diarrhea. $^{7-10}$

Effective antimicrobial therapy is required to control morbidity and mortality from typhoid fever. Until the 1960s, all Salmonella were susceptible to a wide range of antimicrobials. Ampicillin, chloramphenicol, and trimethoprimsulfamethoxazole were the first line drugs for Salmonella. Since 1962, plasmid-mediated resistance has appeared worldwide. Extensive epidemics caused by chloramphenicol resistant Salmonella Typhi were first witnessed in India and Mexico in 1972. ${ }^{11,12}$ By the late 1980s, multidrug-resistant Salmonella resistant to all first line drugs emerged worldwide including in India which is an endemic zone for 50\%-80\% of multidrug-resistant Salmonella. Since 1989, outbreaks by Salmonella Typhi resistant to chloramphenicol, ampicillin, trimethoprim, sulfonamides, streptomycin, and tetracyclines have been reported from India and Pakistan. Multidrugresistant Salmonella has no pathogenic clinical features, though it may present with dominant hepatomegaly, toxicity, or complications and is associated with higher mortality. ${ }^{13-16}$ Ciprofloxacin became the antibacterial of choice for the treatment of typhoid fever after the emergence of Salmonella Typhi strains resistant to chloramphenicol. Ciprofloxacin is also recommended for traveler's diarrhea. However, the minimal inhibitory concentration (MIC) of ciprofloxacin against Salmonella Typhi is gradually increasing due to its continuous use. MIC values for Salmonella Paratyphi A as high as $>126 \mu \mathrm{g} / \mathrm{mL}$ for ampicillin, $256 \mu \mathrm{g} / \mathrm{mL}$ for chloramphenicol, and $64 \mu \mathrm{g} / \mathrm{mL}$ for trimethoprim-sulfamethoxazole have been reported. ${ }^{17-20}$

Ceftriaxone is safe and efficacious against most clinical isolates of Salmonella and is now the preferred drug for MDRTF infections. ${ }^{21,22}$ Reports of resistance to cephalosporins have been appearing at an increasing rate since 2006. It is pertinent to monitor the resistance characteristics of multidrug-resistant Salmonella infections to enable empirical therapy and the treatment of complications. The spread of MDR and fluoroquinolone resistance in Salmonella presents increased clinical challenges in countries where enteric fever is imported, requiring enhanced surveillance. This study characterizes demographical trends, etiological and emerging resistance patterns in typhoidal Salmonella at a 1000-bed teaching hospital in New Delhi, India.

\section{Methods}

This prospective study was conducted among all patients determined to have typhoidal Salmonella infections from blood cultures in a 1000-bed tertiary-care hospital over a period of 6 months after approval was obtained from the Institutional Ethics Committee (ICMR STS 2017-01590). All 200 patients with Salmonella infections detected in blood cultures were included in the study. Typhoidal Salmonella isolated from samples other than blood, patients of nontyphoidal Salmonellosis, and repeat isolates were excluded. Blood samples were collected by skin puncture in Bact/Alert blood culture bottles (Biomerieux, France) following strict aseptic techniques. The quantity of blood drawn was $10 \mathrm{~mL}$ for adults and $5 \mathrm{~mL}$ for children. Samples were immediately transported to the microbiology laboratory for incubation in the Bact/Alert blood culture system (Biomerieux, France) for 2-120 hours. Subcultures on blood and McConkey agars were incubated for $24-48$ hours at $37^{\circ} \mathrm{C}$. Inpatients in pediatrics, obstetrics-gynecology, medicine, the intensive care unit (ICU), and OPD were under surveillance. Organism identification and antimicrobial susceptibility were accomplished using standard microbiology techniques and employing routine bacteriological methods, such as colony characteristics, gram staining, motility, carbon-source utilization, and enzymatic activity, and confirmed by the VITEK-2 Compact Automated Microbiology system (Biomerieux, France). Each patient's demographic profile and non-repeat positive cultures with respective antibiograms were taken into account in the profiling of isolates and antimicrobial susceptibility. Descriptive statistics including frequency, percentages, and 95\% CIs were worked out using Microsoft Excel.

\section{Results}

The age profile revealed mostly young patients up to 40 years of age among both males and females. Mean age was 21.4 years (Figure 1). Most patients (44\%, 95\% CI: 0.35 $0.54)$ were from OPD followed by the pediatric ward $(20 \%$, 95\% CI: 0.13-0.29) (Table 1). Most patients (71\%, 95\% CI: 0.61-0.8) with typhoid fever suffered from Salmonella Typhi followed by Salmonella Paratyphi A (26\%, 95\% CI: 0.18-0.35). Most Salmonella were susceptible to ampicillin, ceftriaxone, trimethoprim-sulfamethoxazole, chloramphenicol and cefepime. Four MDRTF resistant to ampicillin, trimethoprimsulfamethoxazole, and chloramphenicol were encountered. There was no resistance to cefepime among any Salmonella Typhi strains; however, four cases were resistant to ceftriaxone. High degrees of partial and complete resistance to fluoroquinolones were seen among Salmonella Typhi, Salmonella Paratyphi A, and Salmonella Paratyphi B. Resistance to ciprofloxacin was $48 \%$ (95\% CI 0.37-0.6) among Salmonella Typhi and 100\% (95\% CI: 0.9-1) among Salmonella Paratyphi A. Moreover, 18\% (95\% CI: 0.11-0.3) of Salmonella Typhi were completely resistant to quinolones and 79\% (95\% CI: 0.7-0.9) were partially resistant. Additionally, 92\% (95\% CI: 0.8-1) of Salmonella Paratyphi A were partially resistant to quinolones (Table 1).

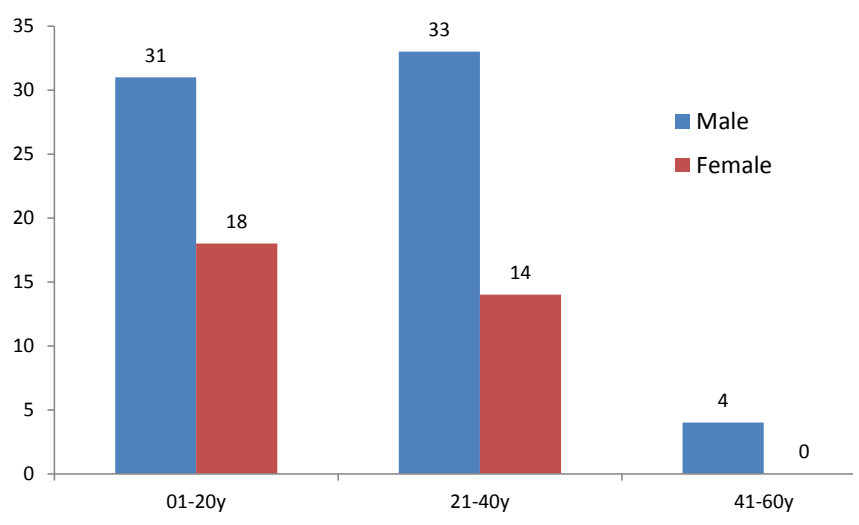

Figure 1. Clinicodemographic Profile of Patients Suffering From Typhoid Fever. 
Table 1. Distribution of Salmonella Typhi, Salmonella Paratyphi A, and Salmonella Paratyphi B in Blood Samples From Various Wards

\begin{tabular}{|c|c|c|c|c|}
\hline WARD & Salmonella Typhi & Salmonella Paratyphi A & Salmonella Paratyphi B & Total \\
\hline Pediatrics, No. (\%) & $16(80)$ & $4(20)$ & $0(0)$ & 20 \\
\hline Obstetrics and gynecology, No. (\%) & $1(100)$ & $0(0)$ & $0(0)$ & 1 \\
\hline Acute medical ward (females), No. (\%) & $5(83.3)$ & $1(16.7)$ & $0(0)$ & 6 \\
\hline ICU, No. (\%) & $0(0)$ & $0(0)$ & $1(100)$ & 1 \\
\hline Acute medical ward (males), No. (\%) & $11(64.7)$ & $6(85.7)$ & $0(0)$ & 17 \\
\hline Subacute medical ward, No. (\%) & $8(72.7)$ & $3(27.3)$ & $0(0)$ & 11 \\
\hline OPD, No. (\%) & $30(68.2)$ & $12(27.3)$ & $2(4.5)$ & 44 \\
\hline Total, No. (\%) & $71(71)$ & $26(26)$ & $3(3)$ & 100 \\
\hline
\end{tabular}

Table 2. Resistance patterns of Salmonella Typhi and Salmonella Paratyphi A and B

\begin{tabular}{|c|c|c|c|c|c|c|c|c|c|c|c|c|c|c|c|}
\hline \multirow{2}{*}{$\mathrm{MIC} \mu \mathrm{g} / \mathrm{mL}$} & \multicolumn{2}{|c|}{ Ampicillin } & \multicolumn{2}{|c|}{ Ceftriaxone } & \multicolumn{2}{|c|}{ Nalidixic Acid } & \multicolumn{2}{|c|}{ Ciprofloxacin } & \multicolumn{2}{|c|}{ Cotrimoxazole } & \multicolumn{2}{|c|}{ Chloramphenicol } & \multicolumn{2}{|c|}{ Cefepime } & \multirow[t]{2}{*}{ Quinolones } \\
\hline & $\leq 8$ & $\geq 32$ & $\leq 1$ & $\geq 4$ & $\leq 8$ & $\geq 32$ & $<1$ & $\geq 1$ & $\leq 8$ & $\geq 32$ & $\leq 8$ & $\geq 32$ & $\leq 2$ & $\geq 16$ & \\
\hline Interpretation & S & $\mathrm{R}$ & $\mathrm{S} / \mathrm{I}$ & $\mathrm{R}$ & $S$ & $\mathrm{R}$ & $\mathrm{S} / \mathrm{I}$ & $\mathrm{R}$ & S & $\mathrm{R}$ & $S$ & $\mathrm{R}$ & $\mathrm{S} / \mathrm{I}$ & $\mathrm{R}$ & \\
\hline S. Typhi & 69 & 2 & 67 & 4 & - & 71 & 37 & 34 & 69 & 2 & 69 & 2 & $69 / 2$ & - & $\begin{array}{c}\text { PR-56 } \\
\text { R-13 }\end{array}$ \\
\hline S. Paratyphi A & 26 & - & $15 / 2$ & 9 & - & 26 & - & 26 & 26 & - & 26 & - & $19 / 5$ & - & PR-24 \\
\hline S. Paratyphi B & 3 & - & - & - & - & - & 3 & - & 3 & - & 3 & - & 3 & - & \\
\hline Total number of isolates & 98 & 2 & 84 & 13 & - & 97 & 40 & 60 & 98 & 2 & 98 & 2 & 100 & - & 93 \\
\hline
\end{tabular}

Susceptible - S, Resistant -R, Intermediate- I, Partially resistant - PR.

\section{Discussion}

Enteric fever is more common in tropical regions because of flooding of rain water, the distribution of sewage into drinking water sources, and increased bacterial concentrations in rivers and streams in the hot and dry season. The distribution of typhoid fever is not well documented in developing countries, because facilities capable of performing the blood culture tests essential for diagnosis are far and few, or because it remains unknown or unaffordable to many patients from resourcelimited communities. The incidence of typhoid fever may be as high as 1000 patients per 100000 population per year in certain regions. In such regions, the excretion of Salmonella Typhi in feces is the main source of infection, and children are predominantly affected. Salmonella infections are associated with poverty; therefore, they tend to cause infections in families and communities. ${ }^{23}$

Travelers to tropical destinations are increasingly at risk of Salmonella infections when traveling to villages or remote rural areas of the countryside where diagnostic and treatment facilities may be far and few. Special precautions are required for travelers with pre-existing bowel/systemic problems such as irritable bowel syndrome, inflammatory bowel disease, poorly controlled diabetes, hepatic cirrhosis, or renal impairment. Patients with a tendency to severe traveler's diarrhea or patients on antacids need to be vigilant in food and water choices while traveling to tropical countries. ${ }^{24-27}$

The current study revealed a young patient profile suffering from Salmonella bacteremia. The high degree of resistance to fluoroquinolones is alarming among all serotypes, viz. Salmonella Typhi, Salmonella Paratyphi A, and Salmonella Paratyphi B. Almost all strains of Salmonella Paratyphi A were resistant to quinolones. Four isolates of multidrugresistant Salmonella showed an increasing trend toward the emergence of resistance in uncomplicated typhoid. The Salmonella serotypes found in this study were $71 \%$ Salmonella Typhi, 26\% Salmonella Paratyphi A, and 3\% Salmonella Paratyphi B, which was in accordance with a study in Indonesia that showed the predominance of Salmonella Typhi over Salmonella Paratyphi. ${ }^{28}$ In the current study, there appears to be an increasing susceptibility to first line drugs such as ampicillin, chloramphenicol, and trimethoprimsulfamethoxazole; i.e. Salmonella Typhi susceptibility to more than three was 99\%. The antimicrobial resistance rates of Salmonella Typhi differ among different countries in the world. A study in Pakistan showed that resistance rates of Salmonella Typhi and Salmonella Paratyphi were 66.1\% for ampicillin, $88.2 \%$ for fluoroquinolone, and $66.5 \%$ for trimethoprim-sulfamethoxazole. ${ }^{29}$ A study in Nepal showed resistance rates of Salmonella Typhi against ampicillin and Salmonella Paratyphi against ciprofloxacin were $1.8 \%$ and $3.9 \%$, respectively, while there was no resistance against trimethoprim-sulfamethoxazole. ${ }^{30}$ Another study in China showed that resistance rates of Salmonella Typhi and Paratyphi were respectively $0.8 \%$ and $2.0 \%$ for ampicillin, $13.5 \%$ and $5.9 \%$ for ciprofloxacin, $5.4 \%$ and $1.4 \%$ for sulfamethoxazole, $5.4 \%$ and $0.8 \%$ for levofloxacin, $10 \%$ and $5.4 \%$ for ceftriaxone, and $0 \%$ for meropenem and imipenem. A study in Bangladesh showed resistance rates were $68.4 \%$ for ampicillin, 39.5\% for ciprofloxacin, 57.9\% for trimethoprim, and $68.4 \%$ for sulfamethoxazole. A study in Vietnam showed $80.4 \%$ for ampicillin, trimethoprim, and sulfamethoxazole, and $0 \%$ for ciprofloxacin, while in Indonesia they were $1.8 \%$ for ampicillin and trimethoprim, $0 \%$ for ciprofloxacin, and $3.6 \%$ for sulfamethoxazole. ${ }^{31}$ Studies from 2001 to 2003 in Indonesia showed that $2.5 \%$ of Salmonella Typhi was resistant to ampicillin, while there was no or very low resistance 
against trimethoprim-sulfamethoxazole, ceftriaxone, or ciprofloxacin ${ }^{13}$ A hospital-based study from 2006 to 2010 in Indonesia also showed similar results; Salmonella Typhi showed no resistance against trimethoprim-sulfamethoxazole, ciprofloxacin, or meropenem, $1.9 \%$ against ampicillin, $0.9 \%$ against ceftriaxone, and $1.6 \%$ against cefotaxime. ${ }^{32} \mathrm{~A}$ study done in Indonesia on the DNA profiles of Salmonella Typhi showed clear differences according to regions, but all the Salmonella Typhi isolates showed similar phenotypes which were susceptible to ampicillin, chloramphenicol, and trimethoprim-sulfamethoxazole. ${ }^{33}$

MDR Salmonella is an emerging problem which has led to increased mortality, particularly in infants and children below five years of age and those who are malnourished. ${ }^{34}$ Nalidixic acid-resistant Salmonella Typhi (NARST) over and above MDR Salmonella reduces treatment options for enteric fever. Ciprofloxacin was the most effective prophylactic antimicrobial and the drug of choice for traveler's diarrhea until the emergence and high prevalence of resistance in Salmonella, Shigella, and Campylobacter. Improvements in public sanitation facilities, the rational use of antibacterials, clean drinking water, safe food handling practices, publichealth education, and mass immunization in endemic areas are required for the prevention of Salmonella infections. Ongoing hospital-based surveillance programs for MDR infections should include Salmonella, which can be traced with epidemiological surveillance. ${ }^{35-38}$ Capacity-building for regional laboratory services and outbreak preparedness are mandated for enhancing contingency and resilience capital of community-based health systems. ${ }^{39-41}$ Typhoidal Salmonella has high epidemic potential amid the emergence of MDR and NARST, and thus forms an important threat in human congregations such as the Kumbh Mela in India, Hajj pilgrimage in Saudi Arabia, and displaced migrant camps. ${ }^{42-44}$ The overlapping epidemicity of Salmonella Typhi and Salmonella Paratyphi A emphasizes a bivalent vaccine covering both as an apparently better choice than a monovalent vaccine in the control strategy of enteric fever.

\section{Conclusion}

Typhoid remains an important public health problem in tropical developing countries threatening both residents and travelers. Salmonella Typhi remains the predominant serotype followed by Salmonella Paratyphi A. The high prevalence of quinolone resistance in Salmonella Typhi and Salmonella Paratyphi A is a serious problem limiting empirical therapy to non-quinolone-based therapy such as ceftriaxone. Multidrugresistant Salmonella is an emerging problem requiring active surveillance among residents and travelers presenting with tropical fever in hospitals, communities, and mass-gathering scenarios.

\section{Authors' Contributions}

All authors contributed equally to this study.

\section{Conflicts of Interest Disclosures}

None.

\section{Research Highlights}

\section{What Is Already Known?}

Typhoid remains a public-health problem in the tropical world, affecting residents and travelers alike. The emergence of multidrug resistance led to outbreaks of typhoidal Salmonella resistant to ampicillin, chloramphenicol, and trimethoprim-sulfamethoxazole in the 1990s. Ceftriaxone is the current drug of choice, because fluoroquinolone resistance limits empirical therapy in both residents and travelers.

\section{What This Study Adds?}

1. High degrees of partial and complete resistance to fluoroquinolones are prevalent among typhoidal Salmonella. Resistance to ceftriaxone is emerging. 2. Multidrug-resistant Salmonella is an emerging problem requiring active surveillance among residents and travelers presenting with tropical fever in hospitals, communities, and mass-gathering scenarios

\section{Ethical Approval}

Ethical approval was covered by the Institutional Committee (ICMR STS 2017-01590).

\section{Funding/Support}

Indian Council of Medical Research STS 2017-01590.

\section{References}

1. Kariuki S, Revathi G, Muyodi J, et al. Characterization of multidrug-resistant typhoid outbreaks in Kenya. J Clin Microbiol. 2004;42(4):1477-1482. doi:10.1128/JCM.42.4.1477-1482.2004.

2. Salve A, Pichel $M$, Wiesner $M$, et al. Molecular subtyping of Salmonella enterica serovar Typhi isolates from Colombia and Argentina. Foodborne Pathog Dis. 2006;3(1):142-152. doi:10.1089/ fpd.2006.3.142.

3. Sinha A, Sazawal S, Kumar R, et al. Typhoid fever in children aged less than 5 years. Lancet. 1999;354(9180):734-737. doi:10.1016/ S0140-6736(98)09001-1.

4. Wain J, Hendriksen RS, Mikoleit ML, Keddy KH, Ochiai RL. Typhoid fever. Lancet. 2015;385(9973):1136-1145. doi:10.1016/S01406736(13)62708-7.

5. Buckle GC, Walker CL, Black RE. Typhoid fever and paratyphoid fever: Systematic review to estimate global morbidity and mortality for 2010. J Glob Health. 2012;2(1):010401. doi:10.7189/ jogh.02.010401.

6. Mogasale V, Maskery B, Ochiai RL, et al. Burden of typhoid fever in low-income and middle-income countries: a systematic, literaturebased update with risk-factor adjustment. Lancet Glob Health. 2014;2(10):e570-580. doi:10.1016/s2214-109x(14)70301-8.

7. Black RE. Epidemiology of travelers' diarrhea and relative importance of various pathogens. Rev Infect Dis. 1990;12 Suppl 1:S73-79. doi:10.1093/clinids/12.Supplement_1.S73.

8. Farthing M, Salam MA, Lindberg G, et al. Acute diarrhea in adults and children: a global perspective. J Clin Gastroenterol. 2013;47(1):1220. doi:10.1097/MCG.0b013e31826df662.

9. Khan ID, Khan SA, Asima B, Hussaini SB, Zakiuddin M, Faisal FA. Morbidity and mortality amongst Indian Hajj pilgrims: A 3-year experience of Indian Hajj medical mission in massgathering medicine. J Infect Public Health. 2017. doi:10.1016/j. jiph.2017.06.004.

10. Masyeni S, Sukmawati H, Paramasatiari L, et al. Diarrhea Among International Travelers in Bali-Indonesia: Clinical and 
Microbiological Finding. Int J Travel Med Glob Health. 2017;5(3):8488. doi:10.15171/ijtmgh.2017.18.

11. Paniker CK, Vimala KN. Transferable chloramphenicol resistance in Salmonella typhi. Nature. 1972;239(5367):109-110. doi:10.1038/239109b0.

12. Olarte J, Galindo E. Salmonella typhi resistant to chloramphenicol, ampicillin, and other antimicrobial agents: strains isolated during an extensive typhoid fever epidemic in Mexico. Antimicrob Agents Chemother. 1973;4(6):597-601. doi:10.1128/AAC.4.6.597.

13. Arora RK, Gupta A, Joshi NM, Kataria VK, Lall P, Anand AC. Multidrug resistant typhoid fever: study of an outbreak in Calcutta. Indian Pediatr. 1992;29(1):61-66.

14. Mishra S, Patwari AK, Anand VK, et al. Multidrug resistant typhoid fever: therapeutic considerations. Indian Pediatr. 1992;29(4):443448.

15. Sharma A, Gathwala G. Clinical profile and outcome in enteric fever. Indian Pediatr. 1993;30(1):47-50.

16. Raman TS, Krishnamurthy L, Menon PK, Singh D, Jayaprakash DG. Clinical profile and therapy in enteric fever. Indian Pediatr. 1994;31(2):196-199.

17. Butt T, Ahmad RN, Salman M, Kazmi SY. Changing trends in drug resistance among typhoid salmonellae in Rawalpindi, Pakistan. East Mediterr Health J. 2005;11(5-6):1038-1044.

18. Chandel DS, Chaudhry R, Dhawan B, Pandey A, Dey AB. Drugresistant Salmonella enterica serotype paratyphi A in India. Emerg Infect Dis. 2000;6(4):420-421. doi:10.3201/eid0604.000420.

19. Qureshi AH, Mushahid N, ljaz A, et al. Changing drug susceptibility pattern of Salmonella Paratyphi A. J Coll Physicians Surg Pak. 2001;11(7):449-451.

20. Woods CW, Murdoch DR, Zimmerman MD, et al. Emergence of Salmonella enterica serotype Paratyphi A as a major cause of enteric fever in Kathmandu, Nepal. Trans R Soc Trop Med Hyg. 2006;100(11):1063-1067. doi:10.1016/j.trstmh.2005.12.011.

21. Chau PY, Ng WS, Ling J, Arnold K. In vitro susceptibility of Salmonella to various antimicrobial agents, including a new cephalosporin, Ro 13-9904. Antimicrob Agents Chemother. 1981;19(1):8-11. doi:10.1128/AAC.19.1.8.

22. Singh L, Cariappa MP. Blood culture isolates and antibiogram of Salmonella: Experience of a tertiary care hospital. Med J Armed Forces India. 2016;72(3):281-284. doi:10.1016/j.mjafi.2015.07.007.

23. Spika JS, Waterman SH, Hoo GW, et al. Chloramphenicolresistant Salmonella newport traced through hamburger to dairy farms. A major persisting source of human salmonellosis in California. N Engl J Med. 1987;316(10):565-570. doi:10.1056/ nejm198703053161001.

24. DuPont HL, Ericsson CD, Farthing MJ, et al. Expert review of the evidence base for prevention of travelers' diarrhea. J Travel Med. 2009;16(3):149-160. doi:10.1111/j.1708-8305.2008.00299.x.

25. Khan ID, Sahni AK. Rapid Diagnosis of Dengue Outbreaks in Resource Limited Facilities. West Indian Med J. 2017;66(1):4-9. doi:10.7727/wimj.2016.095

26. Khan ID. Challenges and Opportunities in Diagnosis and Management of Infectious Diseases in Developing Country Healthcare System. J Basic Clin Med. 2016;5(1):1.

27. Kendall ME, Crim S, Fullerton K, et al. Travel-associated enteric infections diagnosed after return to the United States, Foodborne Diseases Active Surveillance Network (FoodNet), 2004-2009. Clin Infect Dis. 2012;54 Suppl 5:S480-487. doi:10.1093/cid/cis052.

28. Punjabi NH, Agtini MD, Ochiai RL, et al. Enteric fever burden in North Jakarta, Indonesia: a prospective, community-based study. J Infect Dev Ctries. 2013;7(11):781-787. doi:10.3855/jidc.2629
29. Qamar FN, Azmatullah A, Kazi AM, Khan E, Zaidi AK. A three-year review of antimicrobial resistance of Salmonella enterica serovars Typhi and Paratyphi A in Pakistan. J Infect Dev Ctries. 2014;8(8):981986. doi:10.3855/jidc.3817.

30. Chand HJ, Rijal KR, Neupane B, Sharma VK, Jha B. Re-emergence of susceptibility to conventional first line drugs in Salmonella isolates from enteric fever patients in Nepal. J Infect Dev Ctries. 2014;8(11):1483-1487. doi:10.3855/jidc.4228.

31. Chiou CS, Lauderdale TL, Phung DC, et al. Antimicrobial resistance in Salmonella enterica Serovar Typhi isolates from Bangladesh, Indonesia, Taiwan, and Vietnam. Antimicrob Agents Chemother. 2014;58(11):6501-6507. doi:10.1128/aac.03608-14.

32. Alam A. Pola resistensi Salmonella enterica Serotipe typhi, departement Ilmu Kesehatan anak RSHS, Tahun 2006-2010. Sari Pediatri. 2011;12(5):296-301. doi:10.14238/sp12.5.2011.296-301.

33. Moehario LH. The molecular epidemiology of Salmonella Typhi across Indonesia reveals bacterial migration. J Infect Dev Ctries. 2009;3(8):579-584. doi:10.3855/jidc.548.

34. Bhutta ZA. Impact of age and drug resistance on mortality in typhoid fever. Arch Dis Child. 1996;75(3):214-217. doi:10.1136/ adc.75.3.214.

35. Khan ID, Sahni AK, Bharadwaj R, Lall M, Jindal AK, Sashindran VK. Emerging organisms in a tertiary healthcare set up. Med J Armed Forces India. 2014;70(2):120-128. doi:10.1016/j.mjafi.2013.09.005.

36. Khan ID, Basu A, Kiran S, Trivedi S, Pandit P, Chattoraj A. DeviceAssociated Healthcare-Associated Infections (DA-HAI) and the caveat of multiresistance in a multidisciplinary intensive care unit. Med J Armed Forces India. 2017;73(3):222-231. doi:10.1016/j. mjafi.2016.10.008.

37. Jindal AK, Pandya K, Khan ID. Antimicrobial resistance: A public health challenge. Med J Armed Forces India. 2015;71(2):178-181. doi:10.1016/j.mjafi.2014.04.011.

38. Khan ID, Gupta RM, Sen S, et al. Emerging Antimicrobial Resistance and Evolving Healthcare: Dangerous Crossroads for the Community and the Military. J Arch Mil Med. 2017;5(3):e12097. doi:10.5812/ jamm.12097.

39. Khan ID, Gupta N, Rangan NM, et al. Evaluation Of Pre and Post Analytical Variables in Clinical Microbiology Services in Multidisciplinary ICU of a Medical College And Tertiary Care Hospital. J Basic Clin Med. 2016;5(1):2-4.

40. Khan ID, Sahni AK, Sen S, Gupta RM, Basu A. Outbreak of Prototheca wickerhamii algaemia and sepsis in a tertiary care chemotherapy oncology unit. Med J Armed Forces India. 2017. doi:10.1016/j. mjafi.2017.07.012.

41. Khan ID, Lall M, Sen S, Ninawe SM, Chandola P. Multiresistant Elizabethkingia meningoseptica infections in tertiary care. Med J Armed Forces India. 2015;71(3):282-286. doi:10.1016/j. mjafi.2014.02.002.

42. Khan ID, Khan S, Khan MA, et al. Indian Medical Mission at Hajj2016: Mass-Gathering Medicine Perspectives, Challenges, and Opportunities in a Mission Posture. Int J Travel Medicine Glob Health. 2017;5(3):94-101. doi:10.15171/ijtmgh.2017.20.

43. Khan ID, Hussaini SB, Khan S, et al. Emergency Response of Indian Hajj Medical Mission to Heat Illness Among Indian Pilgrims in TentClinics at Mina and Arafat During Hajj, 2016. Int J Travel Med Glob Health. 2017;5(4):135-139. doi:10.15171/ijtmgh.2017.26.

44. Ismayl G, Abdel Hadi H, Hussein A, et al. Practices and Attitudes to Prevention of Travel-related Infectious Diseases in United Arab Emirates. Int J Travel Med Glob Health. 2016;4(1):13-18. doi:10.20286/ijtmgh-040113. 